\title{
Alternative Biome States in terrestrial ecosystems
}

\author{
Juli G. Pausas $\bigotimes^{1,4, *, @ ~ a n d ~ W i l l i a m ~ J . ~ B o n d ~} d^{2,3}$
}

There is growing interest in the application of alternative stable state (ASS) theory to explain major vegetation patterns of the world. Here, we introduce the theory as applied to the puzzle of nonforested (open) biomes growing in climates that are warm and wet enough to support forests (alternative biome states, ABSs). Long thought to be the product of deforestation, diverse lines of evidence indicate that many open ecosystems are ancient. They have also been characterized as 'early successional' even where they persist for millennia. ABS is an alternative framework to that of climate determinism and succession for exploring forest/nonforest mosaics. This framework explains not only tropical forest-savanna landscapes, but also other landscape mosaics across the globe.

\section{Forests and 'Nonforests'}

Traditionally, the distribution of different vegetation types across the world was thought to be driven by climate [1,2], while soil interactions (e.g., competition for resources) wereconsidered the main assembling process [3,4]. One of the clearest arguments suggesting that soil and climatecannotfully explainvegetation distributionistheexistence of mosaics of strikinglydifferent vegetation inthe sameenvironment [5-7]. Many regions of the world can support forests (as indicated by forest patches and forestry plantations) yet are covered by 'nonforest' ecosystems, such as grasslands, prairies, shrublands, or open woodlands (collectively called 'open ecosystems', see Glossary). This mismatch between climate and vegetation has long puzzled ecologists [8-10].

Onecommonexplanationisthatopenecosystemsaretheresultofanthropogenic deforestation, especially through human use of fire and that, given enough time, these 'early successional stages' will transform to a higher biomass ecosystem (forest) as trees shade out smaller growth forms (Table 1). A prominent alternative idea is that open and closed ecosystems share the same landscape because of divergent soil conditions influencing plant growth, with forests growing on soils conducive to tree growth, and open ecosystems on soils hostile to treegrowth. A prediction is then that forests cannot develop on grassland soils, for example. However, as we will see later, diverse lines of evidence have cast doubt on the generality of both sets of explanations.

Athird idea is that open ecosystems aremaintained byecological processes thatconsumetrees, preventing succession to a closed forest. Fire is a prominent and widespread plant consumer withmanyanalogiesto largevertebraeherbivory. Both wildfireand largevertebratescan reduce tree cover, either by killing established trees or by inhibiting their recruitment. Open (consumercontrolled) ecosystems would be predicted to switch to closed forest if the consumer was excludedfromthesystemforlongenoughforforesttreestogrow. Contrarytosuccessiontheory, open ecosystems can be maintained for millennia if the feedback between the plants and the consumer persists.

\section{Highlights}

Therearemanyancientopen vegetation formations worldwide that maintain a highdiversityof shade-intolerantspecies wheretheclimateissuitableforforests.

Fire and herbivores are ancient consumers of plant biomass that maintain open ecosystems and shape shadeintolerant species.

Therefore, open ecosystems are not necessarily either produced by deforestation or early successional, but have been maintained by consumers as ABSs to forests.

ABSs are not only found in tropical environments, but also in temperate and Mediterranean conditions.

'Centro de Investigaciones sobre Desertificación (CIDE-CSIC), 46113 Montcada, Valencia, Spain

${ }^{2}$ Department of Biological Sciences, University of Cape Town, Rondebosch 7701 , Cape Town, South Africa

${ }^{3}$ South African Environmental Observation Network, National Research Foundation, Private Bag X7, Claremont 7735, South Africa

${ }^{4}$ https://www.uv.es/jgpausas/

*juli.g.pausas@ext.uv.es and juli.g.pausas@csic.es (J.G. Pausas). @ Twitter: @jgpausas (J.G. Pausas). 
We currently know that both the open ecosystems and the consumers that maintain them are many millions of years old. Paleoecological [11-16] and phylogenetic [17-20] evidence indicates that fires and large herbivorous tetrapods have been consuming plants for hundreds of millions of years; their impact on ancient ecosystems is currently an active area of research $[11,14,18,19,21,22]$. The sudden dominance of $C_{4}$ grasses during the Miocene is among the most dramatic examples of the assembly of an open ecosystem in the geological record [23-25]. Further evidence for the ancient origin of open ecosystems is the richness and endemism of their biota. Global biodiversity hotspots include open grasslands, shrublands, and savannas rich in endemic shade-intolerant plants and animals, and subject to regular fires or herbivory [26-30]. The existence of a species-rich open habitat biota contradicts the idea that open ecosystems are recent products of deforestation, but supports the evidencethat they are persistent stable habitats [31].

ASS theory has recently emerged from being a theoretical backwater to becoming a major hypothesis for explaining mosaics of open and forested ecosystems around theworld. Here, weintroduce readers to ASS theory by exploring its utility in explaining mosaics of forests and nonforest biomes (ABSs). We discuss why ABS is considered an important contender for explaining the distribution of tropical grassy biomes, and why it may explain many of the forest/ nonforestmosaicselsewhere. Wealsonotepoints of contentionthat causevigorous debate, discuss conservation implications of $A B S$, and indicate new directions and questions raised by the ABS theoretical framework.

\section{Alternative Biome States: The Concept}

The biome concept was first introduced to characterize structurally similar vegetation types in similar climates around the world. Climate classifications, such as that of Koppen, use annual and seasonal means of precipitation and temperatureto categorize climatesthatencompass differentbiomes. Thebiomes, then, aresupposedtorepresentdistinctclimatezones. Thecircularity of this definition (vegetation and climate are indistinguishable) narrowed our understanding of the processesbehind vegetationpatterns.

The problem was recognized, and structural definitions of biomes were developed independent of climate or location. Biomes were instead based on the shared dominance of particular major growthforms within a vegetationtype, butwith different growthformsamong biomes [32]. Consequently, ABSs refer to the potential dominance of different growth forms (and, thus, different biomass, leaf area, shadetolerance, and community structures) under thesame environment, with each state (open versus closed biome) persisting over generations. ABS is a special case of the more general theory of ASS [33-38], which has been applied to a range of biological systems, fromcells to oceans [36]. In such systems, each state returns to thesamestate (stable state) after small disturbances (resilience) thanks to the existence of stabilizing feedback processes [39-41]. However, occasional strong stochastic events (perturbations) or gradual shifts inenvironmental drivers (see[42] foradetailed distinction) can pushthesystemfromonestateto the other (a biome shift); the new state remains stable, while the intermediate situations are unstable. Removing the driver that induced thestate change may not necessarily causethe systemto switch back tothepreviousstate(hysteresis).

Here, we first introduce the case of ABS in the tropics, because it is there where it has been best documented; wethenexaminethedifficulties in testing the ABS and review ABS beyond tropical environments. As feedback mechanisms, we focus on fire and vertebrate herbivory (plant consumers), which have been most widely studied as the major drivers generating ABS at broad scales. Other processes have been proposed as candidates for regime shifts (e.g., freezing,

\section{Glossary}

Basin of attraction (attractor): range of conditionsinwhichanecosystemcan oscillatedueto disturbances, without changingstate(see'Resilience'). Each basin of attraction corresponds to a stablestate. It istypically represented by acup, withaball (ecosystem) oscillating inside it.

Bimodal (multimodal): a frequency distribution with two (or more) peaks. In relation to vegetation mosaics, itrefers to peaksinthefrequency distribution of a vegetationindicator(e.g., treecover, basal area, biomass, ortreedensity) ina given landscape or region

(i.e., intermediate values are rare). Biome: grouping of vegetation types with the same dominant growth form (s) that remains stableover generations. Open and closed biomes (seelater) can be alternative stable states.

Consumers (plant consumers): agents that consume plant biomass generatingfeedbacktothevegetation by influencing their own regime; consumersincludeherbivoresandfire, and consumed-controlled systems include many grasslands, savannas, and shrublands. Consumers convert complex organic compounds into simpler by-products. Note that physical disturbance agents (wind, flood, landslide, etc.) do not consume or convert plant matter, neither is their disturbance regime altered via feedbacks with vegetation. Encroachment (woody encroachment): the increasing dominance of woody plantsina grass-dominated system. Hysteresis: difficult-to-reverse shifts because the two pathways of change between ASSs differ. For instance, grazing may maintain a savanna, and removinggrazersmaydrivethesystem to a forest, but the savanna is not recovered byjustadding backgrazersin the forest.

Landscape anachronism: those landscapes that are best explained by extinct animals and are currently maintained byhumanintervention. Many European landscape mosaics are anachronistic because they include species-rich grasslands currently maintained by livestock or mowing. Open versus closed biomes: open biomesarethosedominated by shade-intolerantplants; theycaninclude some trees, but tree density and leaf areaislowenoughtoallowabundant 
drought, and cyclone damage $[43,44]$ ); however, these are typically of local importance and do notgeneratefeedbacks that maintain one of thestates; thus, they are notconsidered here.

\section{Alternative Biome States Explain Tropical Forest-Savanna Mosaics}

The striking differences and sharp boundaries between tropical forests and tropical grassy biomes (savannas and grasslands; Figure 1) led to early suggestions that they wereecological examples of ABS. ABSs are maintained over generations by stabilizing feedback processes that enhance the conditions required for a given state while hindering the conditions for the other state. Forforest-savannasystemscontrolled byfire(Figure2), themainstabilizingfeedbackprocesses areasfollows [39,40,45-48]: inthelow biomass state (savanna), frequent fires keep the system open and enable a dominance of shade-intolerant flammable grasses that enhance frequentfires. Inthehigherbiomass state(forest), shadelimits thegrowth of flammable (shadeintolerant) grasses, and the higher humidity and the lower wind speed inhibits fire spread while enhancing the growth of forest trees (which further inhibits flammable conditions). Under extreme weather ( $d r y$, hot, and windy) conditions, firemayspreadfromsavannasintotheforestandopen the canopy beyond a light thre shold that allows the colonization of flammable grasses, potentially causing a shift to an open stablestate[10,49]. By contrast, a long fire-free interval may enabletreecolonization of theopenstate, causing eventual exclusion of shade-intoleranttreesand flammable grasses and their replacement by shade-tolerant forest trees $[45,47]$. The regime shift to forests is stabilized by changes in microclimatic conditions and the loss of flammablegrasses (Figure2). Thetwo rates of changeare different(i.e., the basins of attractions areasymmetrical). In general, closed ecosystems cannot easily switch to open ecosystems because forests may be insufficiently flammable, or because the size of the woody species may have exceeded the threshold at which they become fire and/or grazing resistant. Thus, the switch requires an infrequent disturbance event (a perturbation, e.g., a long El Niño/La Niña event; Figure 2 $[10,49,50])$. This difficulty in reverting the state (hysteresis) is a characteristic of many ABSs. The savanna-to-forest switch is slower, but well within the lifespan of a tree, with a tipping point when difficult-to-ignite bush clumps exceed the threshold at which fire no longer 'percolates' through the landscape and the system switches to a nonflammable forest state [51]. The shade-intolerant species. Typical examples are grasslands, savannas, and shrublands. Closed biomes are forests, that is, tree-dominated ecosystems in which the density and leaf areaishighenoughtoexclude shade-intolerant plants in the understory. Closed biomes typically have higher plant biomass than open biomes. Open biomes are often maintained by plant consumers. Open versus closed ecosystems: as for biomes, butin moregeneral terms (i.e., open ecosystems are those dominated byshade-intolerantplants while closed ecosystems are dominated bytrees thatexcludeshade-intolerant plantsintheunderstory). Openversus closed ecosystems should not be confused with open/closed as used in thermodynamics and system theory. Perturbation: disturbance (often infrequent) that shifts the state of a system; also called extrinsic disturbances or destabilizing factors. Notethat not all disturbances generatea perturbation of the system. Resilience: ability to return to the referencestateafter disturbance(i.e., to fluctuate within the basin of attraction), and maintainfunctions, structure, and feedback processes. 'Elasticity' is the speed of the return.

Threshold: point where a small gradual change in conditions lead to large changes (discontinuous jumps) in system state variables (e.g., biomass, number of individuals, or cover).

Table 1. Comparison of the Three Main Dynamic Processes Assembling Disturbance-Prone Communities and Landscapes ${ }^{\mathrm{a}}$

\begin{tabular}{|c|c|c|c|}
\hline Characteristics & Succession & Autosuccession & ABS \\
\hline Mechanisms & Facilitation & Resprouting, seeding & Positive feedbacks \\
\hline Stable states & 1 & 1 & 2 (or more) \\
\hline $\begin{array}{l}\text { Changes inspatial structure } \\
\text { (boundaries) }\end{array}$ & Gradual & No & Abrupt $^{b}$ \\
\hline Temporal changes & Gradual & No & Abrupt $^{\mathrm{b}}$ \\
\hline Community trajectory & Unidirectional & Low, nondirectional & Multidirectional \\
\hline Disturbance & External property & Inherent property & Inherent property \\
\hline Predictability of composition & High (temporal sequence) & Very high & Low \\
\hline Key plant traits & Height, leaf and roottraits, shadetolerance & Bud and seed banks & $\begin{array}{l}\text { Shadetolerance, leaf areaindex, bud bank, } \\
\text { flammability, palatability }\end{array}$ \\
\hline Typical examples & Post volcano, oldfields & Chaparral-type shrublands & Forest-savanna mosaics ${ }^{c}$ \\
\hline
\end{tabular}

aThe three processes compared are: classical (facilitation) succession, autosuccession, and ABSs. Under the ABS framework, autosuccession is understood as a mechanism that maintains an alternative state.

${ }^{b}$ Abruptrelativetothetreelongevity. Notethat, inaquaticecosystems, abruptchangesarefasterthaninterrestrial ecosystemsduetothedifferentgenerationtimes of the organisms.

'See also Table 2 in the main text. 

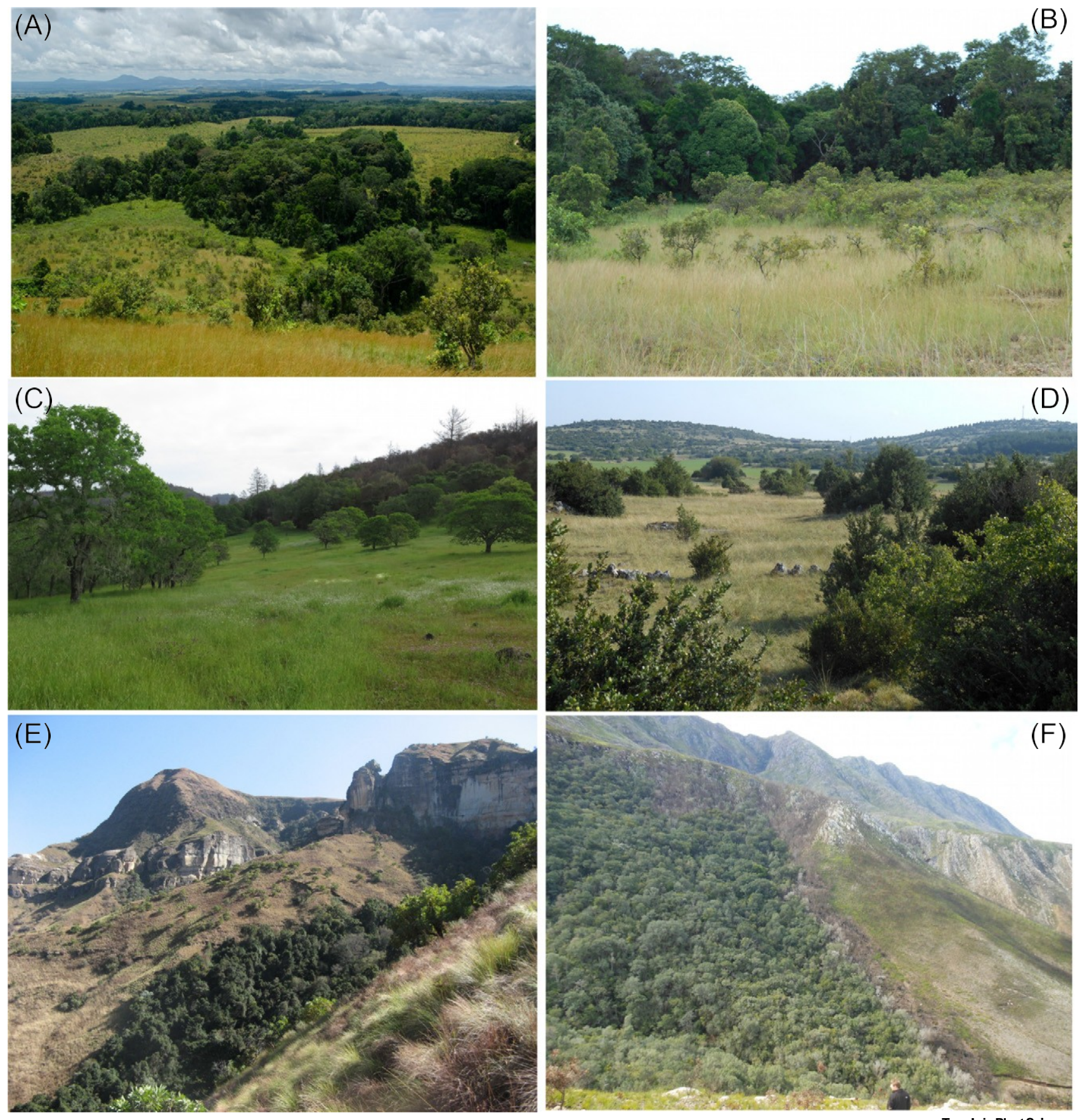

(F)

Figure 1. Examples of Multibiome Landscape Mosaics Where Closed Forests Alternate with Open Biomes (Grasslands and Shrublands) That Are Maintained by Mammal Herbivory and Fire. These examples include tropical (A, B, E); temperate (D); and Mediterranean climates (C, F). Locations: (A,B) Lope, Gabon; (C) Sonoma county, CA, USA; (D) Larzac, France; (E) Drakensberg mountains, South Africa; (F) closed forest and adjacent burnt Cape fynbos, South Africa, showing fire stopping in the forest. Photos by W.J. Bond.

contrasting fire regimes and responses between the two states lead to divergent functional characteristics of the woody plants, as observed in several studies: forest trees typically have thin bark and exposed buds and, thus, are sensitive to grass fires, while trees and shrubs from 
Open biome

Low biomass state

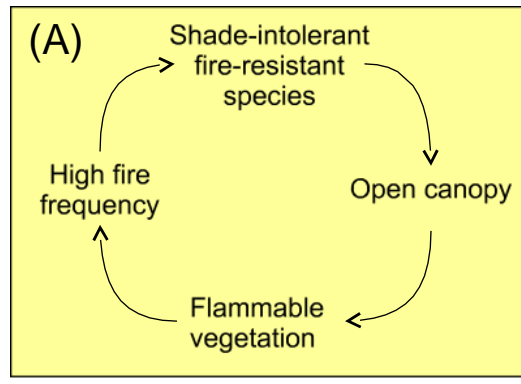

Stabilizing feedback
Closed biome

High biomass state

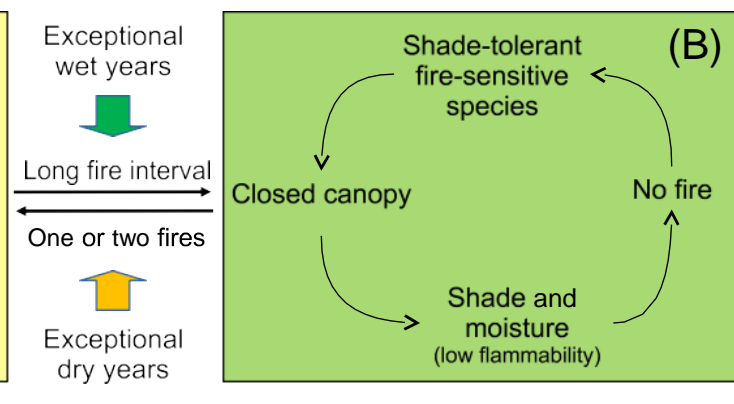

Stabilizing feedback

Perturbations

Trends in Plant Science

Figure 2. Generalized Feedback Processes in Fire-Prone Landscapes Where Open and Closed Biomes (e.g., a Grassland and Forest) Are Stable States Maintained by Stabilizing Feedbacks, While Perturbations Generate Abrupt Transitions among States (Destabilizing Factors). In open ecosystems (A), with lower moisture and higherfirefrequency, woody plants haveless leaf area and invest in fire-resistant mechanisms (thick barkand insulated buds), while in closed canopies (B) with higher shade and moisture, trees shade and inhibit understory plants. In the closed state, one or two consecutive fires (a pulse perturbation) may kill some fire-sensitive trees, open the canopy, and allow the colonization of flammable vegetation, which may surpass the flammability threshold that led to stabilizing the low biomass state. Thisisasuddenandquicktransition. Intheopenstate, along period withoutfires (perturbation) mayallowtheinvasion of fast-growing fire-sensitive trees that close the canopy beyond a threshold that generates enough shade and moisture to stabilizetheclosedcanopystate. Thisshiftmaybeslower. Theopenstate(A) canalsobemaintained byherbivory, enhancing palatablevegetation (grazers) whileinhibiting woody vegetation (browsers). Herbivory exclusion may drivethesystemto a closed woody state, whilebrowsing and firemay revert to thesavannastate [7,39,64].

flammableopenecosystems haveeitherthickfire-resistantbark[45,46,52] orahighresprouting ability fromeitherinsulatedepicormicbuds[53-55] or underground bud banks[20,56].

Whilefire has been extensively studied as a global consumer maintaining open ecosystems, the sameis nottruefor largevertebrateherbivores; thespatial extentand environmental conditions favoring herbivore-maintainedopenecosystemsarestill notwell known. Largevertebrateherbivores, similar to fire, can generate feedbacks by consuming woody vegetation (browsing) while favoring grasses [5,57-59]. Herbivoreexclusion favors the establishment of woody vegetation $[14,60,61]$. Herbivory may maintain grasslands $[7,62-64]$, but a biome switch fromwoodlands to grasslandsmay requirefire $[10,49,65]$. Whileboth herbivory andfire competeforthesameresource(biomass), theirrelativeimportanceinalandscapevaries dependingonarangeoffactors (e.g., herbivores requiremorefertilesoils[64]). Forinstance, inAfrica, thereisa relativelyabrupt shift from herbivory- to fire-controlled systems along a precipitation gradient $[7,64,66]$. Semiarid savannas and nutrient-rich soils support heavy grazing, whereas humid savannas with leached soils support unpalatable vegetation ( high $\mathrm{C} / \mathrm{N}$ ), thereby inhibiting herbivory and promoting fire $[64,67]$. I nsouthern South America, the density of cattlemodulates fireactivityalong theprecipitationgradient[68]. I notherregions, firemayhaveincreasedinimportanceasa plantconsumer, after the extinction of large herbivores $[11,69,70]$.

Given that abrupt transitions among biomes are related to time-dependent processes (e.g., intervals between disturbances and plant growth rate; Figure 2), environmental conditions can influence the dynamics among states by controlling the speed at which the system reaches thresholds. Thus, climate influences the probability of finding alterative biome states, with very wet tropical climates having high probabilities of closed forest, whereas very dry tropical climates 
generally only support grasslands [7,64]. Similarly, spatial heterogeneity in microenvironmental conditions can influencethedynamicsamongstates. Thus, patches of higher soilfertility, deeper soils, or small topographic depressions enhance the transition towards the closed state, while patches of unproductive environment favor open states [71,72].

\section{Testing Alternative Biome States}

Despiteconceptual and modelingadvances in ASS theory, experimental ecologistshavehaddifficulties demonstrating the existence of ABS, particularly because of the high bar set by theoretical ecologists (Box 1 ) and the problem of demonstrating stability in systems with long-lived organisms [40]. ABS theory differs from traditional succession theory in predicting that the openstatesarestableand notearlysuccessional (Table1). However, thestatesarealsodynamic and, thus, the capacity to switch from one state to another must also be demonstrated. Experimental ecologistswouldneed severaldecadestoconvincinglydemonstratethatatreecanrecruit and growto maturity in agrassland, butseveral centuries to convincethemselvesthat an experimental forest can stably occupy the 'grassland' site. Since rigorous long-term experiments are difficult to perform in complexterrestrial ecosystems [38,40,73] (Box 1), manyecologists have overlooked ABS and rely on bottom-up (resource) explanations for biomemosaics [74,75]. The pervasiveideathatforests areancientand nonforests are derived (byhuman deforestation) has been an additional hindranceto unbiased research on the causes of ABS, in which natural disturbances can switch between alternativebiomes[21].

More recently, field ecologists have suggested protocols for testing ABS, emphasizing different features of thetheory. For example, a recent protocol emphasized the dynamism of thealternative states [76] and included demonstrating stability over time using paleoecological and historical data, thensearchingforfield evidence of dynamism(e.g., treegrowth rates and biomeboundary movements), and finally testing it with natural or designed experiments supplemented with simulation models. However, much of the recentsurge of interest in ABSemphasizes pattern, notdynamics, especially thanks to new global remote-sensing information $[6,7,64,77-80]$. These studies reveal that treecover across a precipitation gradient is multimodal and tends to beeither high or low, with few intermediate values. This is consistent with tree densities falling into different basins of attraction, and strongly supports the ABS theory. Subsequent studies have shown

\section{Box 1. The Difficulties of Testing Alternative Biome States in Terrestrial Ecosystems}

ThecriteriaforrecognizingASSswerehotly debated during the1980sand becamestrongly restrictive. The proposed protocol was as follows [35,38]: (i) identify potential alternative states; (ii) apply a range of perturbation levels hypothesized to switch states; (iii) perturbations should mimic natural regimes; (iv) perturbation should not be maintained (pulsedisturbance); (v) the monitoring should be long enough for the alternative state to develop; (vi) perform the reverse experiment, preferablyinthesamesite; and (vii) ifthetwo experimentsareperformedinadifferentsite, then bothexperimentsneedto be well replicated. We could even add: (viii) atmospheric conditions (climate, $\mathrm{CO}_{2}$, or nutrient deposition) during the experiment should reflect thenatural regime. This protocol is difficult to accomplish (if even possible) whenstudying terrestrial ecosystems and long-lived plant species.

Using these criteria, very few studies have demonstrated the existence of alternative states in natural systems [38,73], letalonetheexistenceof alternativebiomes. The criteriaemphasizeexperimental studies, andthis possiblyleadsto afailureto recognize patterns consistent with ABS theory at regional and continental scales. Fireand grazing exclusion experiments are probably the closest approach for testing whether environmental heterogeneity maintains distinct states. Although many such experiments have been maintained for decades, they arestill relatively short in relation to plantlongevity, and nonewere designed fortesting ABS [75]; stabilizing disturbanceand perturbationsoften do notmimicnatural processes. Theexistence of tree plantations in open landscapes is a useful indirect evidence in support of ABS in demonstrating that environmental conditions (soils and climate) are not responsible for excluding forests. Thus, an analysis of patterns should formpart of the criteria for recognizing ABS as a global phenomenon (seeBox 2 in themain text). Alargeand randomized sampling may beneeded to overcomesome of the shortcomings when concluding processes from patterns. 
similar patterns using ground-based analyses of basal area, a surrogate for biomass [7]. By contrast, a unimodal distribution of tree importance would be expected if tree populations were controlled by resourceavailability.

In parallel with the development of remote sensing for broad spatial-scale analyses, the emergence of new paleoproxies provides strong temporal evidence for both stability of states and their potential to shift $[10,14,76]$. For example, thereis isotopic evidencethatcurrent forestsreplaced savannas in southern Africa [81]. Savannas persisted for thousands of years before being replaced by forests, which have now persisted for at least 2000 years [82]. Both states are stable and both occupy soils that can be occupied, and have been, by the other state [82]. Suchstudies havemade it feasible to demonstrate both stability and regime shifts ontimescales far beyond what is practical in field experiments.

However, manipulative and opportunistic experiments are important tests of whether each biome state can occupy the domain of the putative alternativestate. For instance, forest plantations in landscapes dominated by grasslands, prairies, savannas, and shrublands areevidence that the environment is warm and wet enough to support forests. Multidecadal burning experiments show that fire exclusion can transform grasslands to shrublands [83] or closed forests [84-86], whilerecurrentfirescontinueto maintain openecosystemsand savannas. Fireexclusion policies at landscape scales have also shifted open ecosystems to closed forests in both tropical and temperate environments [87-89]. Grazing exclusion experiments show a clear increase in woody biomass [14,60,61], while browsers and mixed feeders reduce woody biomass and favor savannas [39]. However, the level of grazing needed to suppress fire, and the growth rate of trees needed to escape browsing and fire thresholds, depend on system productivity and, thus, in most tropical systems, fire, grazing, and rainfall interact in determining the dynamics of the ABS $[39,64,66,68]$. Therearealso instances where, after decades, fireand/orherbivory exclusion do not trigger shifts to an alternative biome state [90,91]; these are likely caused by edaphic constraints on tree growth, but no synthesis has yet been made. Understanding in which conditions shifts do occur, and in which they do not, is a major research challenge.

\section{Box 2. Identifying Alternative Biome States}

We propose the following requirements for two vegetation types in a landscape to be considered good ABS candidates. None of these requirements may prove the existence of ABS, but together providestrong support for it.

(i) They should differ in the dominant growth formand their aboveground characteristics: typically, open biomes have high light incidence and are dominated by shade-intolerant plants, while closed biomes have higher plant biomass and leafareaindexthatexcludeshade-intolerantplants.

(ii) Theyshouldco-occurinthesameenvironment(seeFigurel inthemaintext), providing theseconditionsareindependent of the system, that is, are not modified by thestates (e.g., topsoil nutrient content is a poor test for ABS). Experimental studies of the potential for a regime shift, such as forest colonization following long-term fire suppression, provide important insights into the suitability of the environment for the alternative state.

(iii) They should differ in their species composition (i.e., the open state is not just a subset of species of the closed state, but has a distinct flora, with a different set of functional traits related to feedbacks that maintain the states). For instance, the degradation of tropical rainforests may generate open ecosystems structurally similar to savannas, yet lacking the specific flora that characterizes ancient savannas [31]. Typically, the open state has plants with disturbance-relatedtraitsthataremissing intheclosed state. Faunaisalso markedly different[26,29].

(iv) They often show abrupt boundaries between each state with limited invasibility, especially for high light-demanding species entering forests. This is typically demonstrated by the existence of a bimodal distribution of a vegetation indicator (e.g., tree density, basal area, and tree cover) across the landscape $[7,77,78]$. Demographic studies may helptoidentifyinstanceswherethejuveniles of colonizing speciesmaytemporarilycoexistwithadultsfromthesystem being invaded.

(v) Theyarestableovergenerations, thatis, therearefeedbackprocessesthatmaintainthestatesand drivethesystemaway fromunstableintermediatestates (seeFigure2inthemaintext) [40,45]. Stabilitycan betested using paleoindicators, such as pollen, phytoliths, andstableisotopiccomposition of organicmatter [40,81]. 
Insummary, therearedifferentways to test the differentassumptions of theABStheory(Box2), and current research suggeststhat the ABS is themostlikelyexplanation for many of thetropical savanna-forest mosaics. Thereis now growing evidencethat ABSalso operates beyond tropical systems [92].

\section{Alternative Biome States Beyond the Tropics}

Among the earliest attempts to understand landscape mosaics were those of Wells in central California [93] andJ ackson in Tasmania [94] during the 1960s. They provided pioneering analyses of multiple stable states in what we would now consider an ABS framework. Both proposed that the complex mosaics of grassland, shrublands, and forests wereexplained by divergent fire regimes, rather than by soils and substrate differences. There is increasing evidence that different biomes in temperate and Mediterranean climates (grasslands, shrublands, broad-leaved forests, and coniferous forests) can overlap in theenvironmental space, co-occur in thelandscape, generate sharp boundaries, and alternate over time in each climate (Table2, Figure 1). Long-term human impactmay blur natural patterns, particularly in Eurasia, hindering our understanding of the drivers shaping temperate landscapes; however, ABS still leaves traces in modern landscapes. For instance, large areas of mountain grasslands in eastern USA and temperate Europearemaintained bygrazing, occasionally with fire, and thecessation of grazing can initiate

Table 2. Examples of Likely ABSs from Nontropical Ecosystems ${ }^{a}$

\begin{tabular}{|c|c|c|c|c|c|}
\hline $\begin{array}{l}\text { Closed biome: higher } \\
\text { biomass state }\end{array}$ & $\begin{array}{l}\text { Perturbations (closed to } \\
\text { open) }\end{array}$ & $\begin{array}{l}\text { Open biome: lower } \\
\text { biomass state }\end{array}$ & $\begin{array}{l}\text { Maintenance of the open } \\
\text { biome }^{b}\end{array}$ & Examples $^{b}$ & Refs \\
\hline $\begin{array}{l}\text { Evergreen broad-leaved } \\
\text { forest }\end{array}$ & Firesin extremeweather & Shrubland & ShortFRI, grazing & SEurope & [102] \\
\hline Serotinous conifer forest & Infrequent very short FRI & Shrubland & ShortFRI & SEurope & $\begin{array}{l}\text { Personal Observation } \\
\text { (Pausas, 2019) }\end{array}$ \\
\hline $\begin{array}{l}\text { Tall (nonserotinous) } \\
\text { coniferous forest }\end{array}$ & $\begin{array}{l}\text { Infrequenthighintensity } \\
\text { crown-fire }\end{array}$ & Shrubland & Frequentcrownfires & SEurope & {$[30,101]$} \\
\hline $\begin{array}{l}\text { Deciduousbroad-leaved } \\
\text { forest }\end{array}$ & Infrequent severe fires & Shrubland & ShortFRI & Patagonia & {$[92,107]$} \\
\hline Broad-leaved forest & Infrequent crown-fire & Coniferous savanna & ShortFRI, other disturbances & SE USA & {$[109,110]$} \\
\hline $\begin{array}{l}\text { Forests (conifers, } \\
\text { broad-leaved) }\end{array}$ & $\begin{array}{l}\text { Climate extremes } \\
\text { (glaciations) }\end{array}$ & Mountain grasslands & Grazing (and fire) & $\begin{array}{l}\text { E USA, CE } \\
\text { Europe }\end{array}$ & [95] \\
\hline $\begin{array}{l}\text { Tundra(including forest } \\
\text { tundra) }\end{array}$ & $\begin{array}{l}\text { Pleistocene grazing, } \\
\text { Pleistocene low- } \mathrm{CO}_{2}\end{array}$ & Steppe & Grazing, trampling & Eurasia & [97] \\
\hline Woodlands & High FI & $\begin{array}{l}\text { Grasslands and/or } \\
\text { shrublands }\end{array}$ & ShortFRI & $\begin{array}{l}\text { GreatPlain, } \\
\text { USA }\end{array}$ & [83] \\
\hline Forest & Fire, herbivory & Wood pastures & Mammal herbivory & Europe & [57] \\
\hline Shrubland & ShortFRI and grazing & Grassland & ShortFRI and grazing & $\begin{array}{l}\text { GreatPlain, } \\
\text { USA }\end{array}$ & [135] \\
\hline Forested wetland & Fire & Nonforested wetland & $\begin{array}{l}\text { Low transpiration and interception; } \\
\text { water-logging }\end{array}$ & $\begin{array}{l}\text { Tasmania, } \\
\text { AU }\end{array}$ & [10] \\
\hline Forest & HighFI & Sedgeland/shrubland & Short FRI & $\begin{array}{l}\text { Tasmania, } \\
\text { AU }\end{array}$ & {$[76,94]$} \\
\hline Forest & Browsing + Fire & Oak savanna & Browsing & Canada & [63] \\
\hline $\begin{array}{l}\text { Broad-leaved } \\
\text { deciduous }\end{array}$ & $\begin{array}{l}\text { LongFRI, accumulation of } \\
\text { peat }\end{array}$ & Conifer forest & PredictableFRI of lowFI & Boreal & {$[113,114]$} \\
\hline
\end{tabular}

apen and closed biomes represent two ASSs. Perturbations switching the closed state to the open state, and the processes maintaining these open lower biomass states are also shown based on the examples indicated. Perturbations related to fire are often tied to infrequent extreme weather and/or climate events, but the main direct (mechanistic) effect is fire and not drought. This is not an exhaustive list.

${ }^{\mathrm{b}}$ Abbreviations: CE, central-east; $\mathrm{E}$, east; FRI, fire return interval; S, south; SE, south-east. 
encroachment bytrees $[95,96]$; thissuggests that forestsand temperategrasslands areABSs. Similarly, largeareas of cold steppes aremaintained by grazing, and a decreasein grazing drives the systemto a tundra state with sometrees [97]. Although temperategrasslands are currently mainly maintained by livestock or mowing, there is evidence of a long history of grazing in these ecosystems $[14,57,62,67,98]$. Megafauna collapse coincided with the arrival of early human populations, butmany herbivores (e.g., elk, deer, bison, horses, and wild cattle) remained at significant densities, as reproduced in the wall of numerous Paleolithic caves in Europe, and reported by early travelers in America [95]. Thus, domestic livestock may have replaced Pleistocene grazers in maintaining ancient open ecosystems $[57,98]$. In some regions, it is likely that the loss of the Pleistocene megaherbivores would have led to a substantial reduction in grasslands and plant diversity in favor of forest and tundra $[67,95,97,99]$. In fact, fossil dung beetles in Europe indicate that vegetation was moreopen during the last I nterglacial than after the megafauna extinctions [15]. Thus, sharp grassland-forest boundaries currently maintained by livestock or mowing may be a landscape anachronism of a previous natural system.

A relatively well-documented ABS is the oak savanna and forest in temperate North America $[61,63]$. Many of these oaksavannas are maintained by deer browsing, which suppresses forest tree regeneration. This favors unpalatable species, some of which are highly competitive under high light incidence, and this further suppresses tree regeneration. In addition, the openness makes large forest trees more susceptible to windstorms. These feedbacks maintain open savannas as stable states; a reduction in deer populations is usually insufficient to causea regime shift to a forest [61,63]. Similar processes (feedback and hysteresis) have been documented in areas with introduced browsers[100].

In many nontropical environments, forests alternate with shrublands that have a radically different species assemblage (Table 2). While in temperate and cold environments, ABS appears to be driven by herbivores (above), in warmer Mediterranean conditions, species-rich chaparral-type shrublands are often maintained by regular fires [30,101,102]. For instance, in South Africa, patches of evergreen forest occur in landscapes dominated by flammable fynbos shrublands on some of the most nutrient-poor soils in the world [102-104]. Here, the ABSs have major effects on the chemistry of quartzite-derived soils, with forests enriching the soil and fynbos maintaining very low nutrient concentrations [104], reinforcing the divergence of the two states. Mediterranean shrublands are among the most species-rich ecosystems in the world [30,105], yet they grow in environments that can sustain high biomass forests, including tall eucalypt (Australia) and redwood (California) forests, as well as vast forest plantations. In these Mediterranean conditions, extreme changes in fire regime can drive a coniferous forest to a shrubland. Such is the case under a reduced fire return interval in serotinous trees, or after an increased fire intensity in nonserotinous treeforests. Oncethe system has shifted to ashrubland, itcan remain stable under relatively frequent fires of high intensity (traditionally termed 'autosuccession'; Table 1) with a species-rich shade-intolerant flora with high postfire regeneration capacity $[30,106]$. These fire-dependent forest-shrubland mosaics also occur in colder environments $[92,107,108]$.

Thealternation of fire-maintained open vegetationand fire-resistantbroad-leavedforestsisalso well known in temperate warm ecosystems, especially in the eastern USA (Table 2). Frequent grass-fueled fires maintain pine and oak savannas, while fire suppression promotes closed broad-leaved forests with contrasting shade, fire regimes, and feedbacks [88,109,110]. In boreal ecosystems, theseforest mosaics may bedriven by ungulate browsing and budwormoutbreaks $[111,112]$ or changing fire regimes [113]. Studies in Alaska have shown that needle-leaved (conifer) boreal forests switch to broad-leaved (angiosperm) forests after intense fires when 
theseconvertorganictomineral soils[114]. Besidessuggesting the potential for extremely rapid vegetation change in the future [113], these studies also suggest the possibility of ABS if the broad-leaved forests are maintained for long periods (a century or two); otherwise, the switch back to a conifer-dominated ecosystem would be an example of classic succession.

Implications for Conservation in a Changing World

Open ecosystems harbor a huge diversity of light-demanding species and species that require largeopenhabitats [115]; mostofthesespecies cannotliveinforests. I naddition, manybiodiversityhotspotsaresavannasand shrublands maintained byfire; indeed, fireisastrong driver of biodiversity [116]. Thus, the ABS provides a framework for the conservation of landscape mosaics where different alternative states coexist in an ecologically and evolutionary dynamic way. Classical succession theory suggests markedly different (narrower) conservation priorities because open ecosystems are considered transient (immature, nonoptimal), and fire and herbivory are viewed as processes that delay succession towards the optimum. Thus, an ABS perspective on conservation management can be seen as promoting fire as essential for conserving the open state, whereas a succession approach is more likely to suppress fire as a process preventingsuccessionto a forestclimax.

Global warming is increasing the probability of heat waves and intensefires and, thus, itmayenhance the tendency towards open ecosystems. However, increasing atmospheric $\mathrm{CO}_{2}$, the abandonmentof rural activities (e.g., livestock), andstrongfiresuppression insomeecosystems are promoting woody encroachment worldwide and threatening ancient open habitats $[117,118]$. Afforestation of open ecosystems for $\mathrm{CO}_{2}$ sequestration has been widely promoted and is a growing threattotheirfuture[119]. Thisis despitegreatuncertaintyastotheeffectiveness of afforestation as a carbon sinkand the disruptivesocial, economic, and ecological consequences of landcover change over enormous areas [119-121]. Anthropogenic defaunation of large herbivores (e.g., poaching or habitat fragmentation) is another threat to ABS landscapes. Managing these landscapes should include the management of consumer regimes because they can alter biome trajectories and even alleviate some of the effects of global change [28,122-125]. Prescribed fires and wildfire management are becoming keyoptions in many ABS landscapes [126]. Rewilding [127] is another management option increasingly considered for restoring landscape mosaics, although its application is still limited. The ABS framework also provides an indication of when management strategies can make significant changes for conservation (e.g., close to the thresholds) and when they would fail [128].

ABS has also implication for species distribution modeling under climatic change, because this technique often assumes that species respond individualistically to climate. Given that plants in ABS landscapes respond within a biome, changes in species distribution are not expected if the biome does not change. Thus, in ABS landscapes, predictions based on individual species responsetoenvironment are likely to be poor.

Overall, ABSprovidestheappropriateframeworkfortheconservation of thedifferentalternative states, and the processes that maintainthem.

\section{Concluding Remarks}

Despite the difficulties in performing rigorous long-term experimental tests to demonstrate terrestrial biome shifts under a given environment (Box 1 ), there are diverse lines of evidence suggesting that ABS arecommon in the tropics and beyond. However, therelativeimportance of ABS versus successional processes or fixed soil constraints on vegetation distribution remains to be quantified in different regions and environments (see Outstanding Questions). ABS theory providesa 
valuablealternative framework for understanding spatial and temporal vegetation patternsthat differ from those based on gradual changes (e. g., gradient analysis and succession), and suggests that multistability in a given environment is common. This view has somestartling implications: for example, instead of asking how organisms fittheenvironment, weneed to ask how the organismcanchangetheenvironmenttofittheorganism(nicheconstruction). Whileclassicsuccessiontheorysuggeststhatcommunitieschangeasspeciesmodifytheirenvironment, makingit morefavorableforlatersuccessional species, theABS perspectiveis thatspeciesmodify their environment, making it more favorable for their own continued occupancy (Table 1, Figure 2), which is betteraligned withaDarwinian view of nature.

One of the advantages of the ABS is that disturbances (plant consumers) are well integrated into the system in contrast to classical successional theory (based on facilitation and competition), where disturbance is an external factor that reverts succession (Table 1). The ABS framework highlights fire and vertebrate herbivory as the key processes promoting $A B S$ since both affect the plants growing in a community and, in turn, the plants influence the activities of both consumers (feedback). The relative role of each consumer requires further research (see Outstanding Questions), but is likely to depend on historical contingencies and productivity; for instance, fires dominate at intermediate productivity [129] and where herbivores were decimated (e. g., Pleistocene overkill); and herbivores tend to be important where fires are limited (too dry or too moist). There is growing evidence that disturbance regimes affect plant biomass and select for distinct strategies. Thus, ABS also provides the appropriate context for the evolution of contrasting functional traits in plants $[19,46,130,131]$ and animals $[29,132]$. Of particular importancetothe idea of consumer control and feedbacks between the consumer and the ecosystem is whether plants have evolved to promote the consumer and the associated disturbance regime (see Outstanding Questions). For example, there is considerable interest in whether plants haveevolved flammability, promoting fire, or palatability, promoting increased grazing, with feedbacks to ecosystem properties [133,134].

Thus, is it not timeto broaden the idea found in most biogeography textbooks that climatecontrolsthemajorvegetationformations of theworld totherichernotion of consumercontrol? Working within climaticand edaphic constraints and depending on the plant species pool, consumers can produce vastly differentecosystems fromthe climate potential and havedoneso for millions of years.

Acknowledgments

This work was performed under the framework of the FILAS (CGL2015-64086-P), FIROTIC (PGC2018-096569-B-I00), and FOCSEC (PROMETEO/2016/021) projects from the Spanish Government and the Generalitat Valenciana for J.G.P., and the Biome Boundaries project supported by the Andrew Mellon Foundation and the National Research Foundation of South Africa for W.J .B. We thank the 'Coach \& Horses' Hotel (Richmond, UK) for inadvertently holding two project meetings.

References

1. Holdridge, L. (1947) Determination of world plant formations fromsimple climatic data. Science 105, 267-268

2. Whittaker, R.H. (1975) Community and Ecosystems (2nd edn), MacMillan

3. MacArthur, R. and Levins, R. (1967) The limiting similarity, convergence, and divergence of coexisting species. Am. Nat. 101, 377-385

4. Diamond, J.M. (1975) Assembly of species communities. In Ecology and Evolution of Communities (Cody, M. and Diamond, J., eds), pp. 342-444, Harvard University Press

5. Sankaran, M. et al. (2005) Determinants of woody cover in Africansavannas. Nature 846-849
6. Staver, A.C. etal. (2011) Theglobal extentanddeterminantsof savanna and forest as alternative biome states. Science 334, 230-232

7. Dantas, V.L. et al. (2016) Disturbance maintains alternative biome states. Ecol. Lett. 19, 12-19

8. Bowman, D.M.J.S. (2000) Australian Rainforests: Islands of Green in a Land of Fire, Cambridge University Press

9. Bond, W.J. (2008) What limits trees in C4 grasslands and savannas? Annu. Rev. Ecol. Evol. Syst. 39, 641-659

10. Fletcher, M.-S. et al. (2014) A fire driven shift from forest to non-forest: evidenceforalternativestablestates? Ecology 95 , 2504-2513 
11. Barnosky, A.D. et al. (2016) Variable impact of lateQuaternary megafaunal extinction in causing ecologica state shifts in North and South America. Proc. Natl. Acad. Sci. U. S. A. 113, 856-861

12. Pausas, J.G. and Keeley, J.E. (2009) A burning story: the role of fire in the history of life. BioScience 59, 593-601

13. Bond, W.J. and Scott, A.C. (2010) Fire and the spread of flowering plants in the Cretaceous. New Phytol. 188, 1137-1150

14. Bakker, E.S. et al. (2016) Combining paleo-data and modern exclosureexperimentstoassesstheimpactofmegafaunaextinctionson woody vegetation. Proc. Natl. Acad. Sci. 113, 847-855

15. Sandom, C.J. et al. (2014) High herbivore density associated with vegetation diversity in interglacial ecosystems. Proc. Natl. Acad. Sci. U. S. A. 111, 4162-4167

16. MacFadden, B.J . (2005) Fossil horses- evidencefor evolution Science 307, 1728-1730

17. He, T.etal. (2012) Fire-adaptedtraits of Pinus aroseinthefier Cretaceous. New Phytol. 194, 751-759

18. He, T. and Lamont, B.B. (2018) Baptismby fire: the pivotal role of ancient conflagrations in evolution of the Earth's flora. Nat/. Sci. Rev. 5, 237-254

19. Charles-Dominique, T. et al. (2016) Spiny plants, mammal browsers, and the origin of African savannas. Proc. Natl. Acad Sci. U. S. A. 113, E5572-E5579

20. Pausas, J.G. et al. (2018) Unearthing belowground bud banks in fire-proneecosystems. New Phytol. 217, 1435-1448

21. Pausas, J.G. and Bond, W.J. (2019) Humboldt and the reinvention of nature. J. Ecol. 107, 1031-1037

22. Sulej, T. and Niedźwiedzki, G. (2019) An elephant-sized Late Triassic synapsid with erect limbs. Science 363, 78-80

23. Keeley, J .E. and Rundel, P.W. (2005) Fireand the Miocene expansion of $\mathrm{C}_{4}$ grasslands. Ecol. Lett. 8, 683-690

24. Edwards, E.J . et al. (2010) The origins of C4 grasslands: Integrating evolutionary and ecosystem science. Science 328, 587-591

25. Strömberg, C.A.E. (2011) Evolution of grasses and grassland ecosystems. Annu Rev. Earth Planet. Sci. 39, 517-544

26. Murphy, B.P. et al. (2016) The underestimated biodiversity of tropical grassy biomes. Philos. Trans. R. Soc. Lond. B Biol. Sci. 371, 1703

27. Silveira, F.A.O. et al. (2016) Ecology and evolution of plant diversityintheendangeredcamporupestre: aneglectedconservation priority. Plant Soil 403, 129-152

28. Kaarlejärvi, E. et al. (2017) Herbivores rescue diversity in warmingtundrabymodulating trait-dependentspecies losses and gains. Nat. Commun. 8, 419

29. Pausas, J.G. and Parr, C. L. (2018) Towards an understanding of the evolutionary role of fire in animals. Evol. Ecol. 32, 113-125

30. Keeley, J. E. et al. (2012) Fire in Mediterranean Ecosystems: Ecology, Evolution and Management, Cambridge University Press

31. Veldman, J.W. et al. (2015) Toward an old-growth concept for grasslands, savannas, and woodlands. Front. Ecol. Environ. $13,154-162$

32. Moncrieff, G.R. etal. (2016) Revisingthebiomeconceptfor un derstanding and predicting global change impacts. J. Biogeogr. 43, 863-873

33. Lewontin, R.C. (1969) The meaning of stability. In Diversity and Stability in Ecological Systems (Woodwell, G.M. and Smith, H.H., eds), pp. 12-24, Brookhaven National Laboratory

34. May, R.M. (1977) Thresholds and breakpoints in ecosystems with a multiplicity of stablestates. Nature 269, 471-477

35. Connell, J.H. and Sousa, W.P. (1983) On the evidence needed to judge ecological stability or persistence. Am. Nat. 121, 789-824

36. Scheffer, M. and Carpenter, S.R. (2003) Catastrophic regime shifts in ecosystems: linking theory to observation. Trends Ecol. Evol. 18, 648-656

37. Scheffer, M. et al. (2015) Early warning signals of critical ecological transitions. Annu. Rev. Ecol. Evol. Syst. 461, 53-59

38. Petraitis, P. (2013) Multiple Stable States in Natural Ecosystems, OxfordUniversity Press

39. van Langevelde, F. et al. (2003) Effects of fireand herbivoryon thestability of savanna ecosystems. Ecology 84, 337-350
Bowman, D.M.J.S. et al. (2015) Feedbacks and landscapelevel vegetation dynamics. Trends Ecol. Evol. 30, 255-260

41. Wilson, J.B. and Agnew, A.D.Q. (1992) Positive-feedback switches in plant communities. Adv. Ecol. Res. 23, 263-336

42. Beisner, B.E. et al. (2003) Alternativestable states in ecology. Front. Ecol. Environ. 1, 376-382

43. Fensham, R.J . and Holman, J.E. (1999) Temporal and spatial patterns in drought-related tree dieback in Australian savanna. J. Appl. Ecol. 36, 1035-1050

44. Allen, C.D. et al. (2010) Aglobal overview of droughtand heatinduced tree mortality reveals emerging climate change risks forforests. For. Ecol. Manag. 259, 660-684

45. Hoffmann, W.A. etal. (2012) Ecologicalthresholdsatthesavannaforest boundary: how plant traits, resources and fire govern the distribution of tropical biomes. Ecol. Lett. 15, 759-768

46. Dantas, V.L. et al. (2013) Fire drives functional thresholds on the savanna-forest transition. Ecology 94, 2454-2463

47. Charles-Dominique, T.etal. (2018) Steal thelight: shadevsfire adapted vegetation in forest-savanna mosaics. New Phytol. 218, 1419-1429

48. Pausas, J.G. and Dantas, V.L. (2017) Scale matters: firevegetation feedbacks are needed to explain tropical tree cover at the local scale. Glob. Ecol. Biogeogr. 26, 395-399

49. Browne, C. and Bond, W. (2011) Firestorms in savanna and forest ecosystems: curse or cure? Veld Flora 97, 62-63

50. Keeley, J.E. and Pausas, J.G. (2019) Distinguishing disturbance from perturbations in fire-prone ecosystems. Int. J. Wildland Fire 28, 282-287

51. Schertzer, E etal. (2015) Implications of the spatial dynamics of fire spread for the bistability of savanna and forest. J. Math. Biol. 70, 329-341

52. Pausas, J.G. (2015) Bark thickness and fire regime. Funct. Ecol. 29, 315-327

53. Burrows, G.E. (2002) Epicormic strand structure in Angophora, Eucalyptus and Lophostemon (Myrtaceae) - implications for fire resistance and recovery. New Phytol. 153, 111-131

54. Pausas, J.G. and Keeley, J.E. (2017) Epicormic resprouting in fire-prone ecosystems. Trends Plant Sci. 22, 1008-1015

55. Charles-Dominique, T. et al. (2015) Bud protection: a key trait for species sorting in a forest-savanna mosaic. New Phytol. 207, 1052-1060

56. Maurin, O. et al. (2014) Savanna fire and the origins of the "underground forests' of Africa. New Phytol. 204, 201-214

57. Vera, F.W.M. et al. (2006) Large herbivores: missing partners of westernEuropean light-demanding treeand shrubspecies? In Large Herbivore Ecology, Ecosystem Dynamics and Conservation (Danell, K. et al., eds), pp. 203-231, Cambridge UniversityPress

58. Asner, G.P. et al. (2009) Large-scale impacts of herbivores on the structural diversity of African savannas. Proc. Natl. Acad. Sci. 106, 4947-4952

59. Staver, A.C. and Bond, W.J . (2014) Is there a 'browse trap'? Dynamics of herbivore impacts on trees and grasses in an African savanna. J. Ecol. 102, 595-602

60. Ripple, W.J . and Beschta, R.L. (2003) Wolf reintroduction, pre dation risk, and cottonwood recovery in Yellowstone National Park. For. Ecol. Manag. 184, 299-313

61. Tanentzap, A.J et al. (2012) Slow responses of ecosystems to reductions in deer (Cervidae) populations and strategies for achieving recovery. For. Ecol. Manag. 264, 159-166

62. Bakker, $\mathrm{C} . \mathrm{H}$. et al. (2004) Ecological anachronisms in the re cruitment of temperate light-demanding tree species in wooded pastures. J. Appl. Ecol. 41, 571-582

63. Tanentzap, A.J . et al. (2011) Seeing theforest for the deer: do reductions in deer-disturbance lead to forest recovery? Biol. Conserv. 144, 376-382

64. Archibald, S. and Hempson, G.P. (2016) Competing consumers: contrasting the patterns and impacts of fireandmam malian herbivory in Africa. Philos. Trans. R. Soc. Lond. B Biol. Sci. 371, 20150309

65. Donaldson, J.E. et al. (2018) Ecological engineering through fire-herbivoryfeedbacks drivestheformation of savannagrazing lawns. J. Appl. Ecol. 55, 225-235

66. Hempson, G.P.etal. (2019) Alternategrassyecosystemstates are determined by palatability-flammability trade-offs. Trends Ecol. Evol. 34, 286-290 
67. Venter, ZS. et al. (2017) I mplications of historical interactions between herbivory and fire for rangeland management in African savannas. Ecosphere 8, e01946

68. Bernardi, R.E. et al. (2016) Why are forests so scarce in subtropical South America? The shaping roles of climate, fire and livestock. For. Ecol. Manag. 363, 212-217

69. Gill, J.L. et al. (2009) Pleistocene megafaunal collapse, nove plant communities, and enhanced fire regimes in North America. Science 326, 1100-1103

70. Rule, S. et al. (2012) The aftermath of megafaunal extinction: ecosystem transformation in Pleistocene Australia. Science 335, 1483-1486

71. Kellman, M. (1984) Synergistic relationships between fire and low soil fertility in Neotropical savannas: a hypothesis. Biotropica 16, 158-160

72. Ondei, S. et al. (2017) Water, land, fire, and forest: multi-scale determinants of rainforests in the Australian monsoon tropics. Ecol. Evol. 7, 1592-1604

73. Schröder, A. et al. (2005) Direct experimental evidence for alternativestablestates: areview. Oikos 110, 3-19

74. Mills, A.J .etal. (2016) Apreliminarytestof catabolicnutrientsin explanation of the puzzling treelessness of grassland in mesic Australia. AustralEcol. 41,927-937

75. Veenendaal, E.M. etal. (2018) Ontherelationshipbetweenfire regime and vegetation structure in the tropics. New Phytol. 218, 153-166

76. Bowman, D.M.J.S. and Perry, G.L.W. (2017) Soil or fire: what causes treeless sedgelands in Tasmanian wet forests? Plant Soil 420, 1-18

77. Hirota, M. et al. (2011) Global resilience of tropical forest and savannato critical transitions. Science 334, 232-235

78. van Nes, E.H. et al. (2018) Fire forbids fifty-fifty forest. PLoS One 13, e0191027

79. Staal, A. etal. (2016) Bistability, spatial interaction, andthedis tribution of tropical forests and savannas. Ecosystems 19, 1080-1091

80. Scheffer, M. et al. (2012) Thresholds for boreal biome transitions. Proc. Natl. Acad. Sci. 109, 21384-21389

81. West, A.G. et al. (2000) Soil carbon isotopes reveal ancient grassland under forest in Hluhluwe, KwaZulu-Natal. S. Afr. J. Sci. 96,252

82. Gillson, L. (2015) Evidence of a tipping point in a southern African savanna? Ecol. Complex. 21, 78-86

83. Ratajczak, Z et al. (2014) Fire dynamics distinguish grasslands, shrublands and woodlands as alternative attractors in the Central Great Plains of North America. J. Ecol. 102 1374-1385

84. Woinarski, J.C.Z. et al. (2004) Response of vegetationand vertebratefaunato 23years of fireexclusion in atropical Eucalyp tus open forest, Northern Territory, Australia. Austral. Ecol. 29, 156-176

85. Bond, W.J . et al. (2005) The global distribution of ecosystems in a world without fire. New Phytol. 165, 525-538

86. Durigan, G and Ratter, J A. (2006) Successional changes in cerrado and cerrado/forest ecotonal vegetation in western São Paulo state, Brazil, 1962-2000. Edinb. J. Bot. 63, 119-130

87. Covington, W.W. and Moore, M.M. (1994) Southwestern Ponderosaforeststructure: changessinceEuro-Americansettlement. J. For. 92, 39-47

88. Peterson, D.W. and Reich, P. B. (2001) Prescribed fire in oak savanna: firefrequency effects onstand structureand dynamics. Ecol. Appl. 11, 914-927

89. Geiger, E.L. et al. (2011) Distinct roles of savanna and forest tree species in regeneration under fire suppression in a Braziliansavanna. J. Veg. Sci. 22, 312-321

90. Lloyd, J. et al. (2015) Edaphic, structural and physiologica contrasts across Amazon Basin forest-savanna ecotones suggesta rolefor potassiumas a key modulator of tropical woody vegetation structure and function. Biogeosciences 12 6529-6571

91. Staal, A. and Flores, B.M. (2015) Sharp ecotones spark sharp ideas: comment on "Structural, physiognomic and aboveground biomass variation in savanna-forest transition zones on three continents - how different are co-occurring savanna and forest formations?" by Veenendaal et al. (2015). Biogeosciences 12, 5563-5566

92. Pausas, J.G. (2015) Alternative fire-driven vegetation states. J. Veg. Sci. 26, 4-6

93. Wells, P.V. (1962) Vegetation in relation to geological substratum and fire in the San Luis Obispo quadrangle, California. Ecol. Monogr. 32, 79-103

94. Jackson, W. (1968) Fire, air, water and earth—an elementa ecology of Tasmania. Proc. Ecol. Soc. Aust. 3, 9-16

95. Weigl, P.D. and Knowles, T.W. (2014) Temperate mountain grasslands: aclimate-herbivorehypothesisfororiginsand persistence. Biol. Rev. 89, 466-476

96. Hájková, P. etal (2018) Persistenceofavegetationmosaicina peripheral region: could turbulent medieval history disrupt Holocene continuity of extremely species-rich grasslands? Veg. Hist. Archaeobotany 27, 591-610

97. Zimov, S.A.etal. (1995) Steppe-tundratransition: aherbivore driven biome shift at the end of the Pleistocene. Am. Nat 765-794

98. Bocherens, $\mathrm{H}$. (2018) The rise of the anthroposphere since 50,000 years: an ecological replacement of megaherbivores by humans in terrestrial ecosystems? Front. Ecol. Evol. 6, 3

99. Willerslev, E.etal. (2014) Fiftythousand years of Arcticvegetation and megafaunal diet. Nature 506, 47

100. Wright, D.M. et al. (2012) I mpacts of culling and exclusion of browsers on vegetation recovery across New Zealand forests. Biol. Conserv. 153, 64-71

101. Odion, D.C. et al. (2010) Alternative community states maintained by fire in the Klamath Mountains, USA. J. Ecol. 98 , 96-105

102. Coetsee, C. et al. (2015) Forest and fynbos are alternative states on the same nutrient poor geological substrate. S. Afr. J. Bot. 101, 57-65

103. Manders, P.T. (1990) Fire and other variables as determinants of forest/fynbos boundaries in the Cape Province. J. Veg. Sci. $1,483-490$

104. Cramer, M.D. etal. (2019) Areforest-shrublandmosaics of the Cape Floristic Region an example of alternate stable states? Ecography 42, 717-729

105. Rundel, P. et al. (2018) Fire and plant diversification in Mediterranean-climateregions. Front. PlantSci. 9, 851

106. Pausas, J.G. etal. (2004) Plantfunctional traits in relationtofire in crown-fireecosystems. Ecology 85, 1085-1100

107. Paritsis, J. et al. (2015) Positive fire feedbacks contribute to shifts from Nothofagus pumilio forests to fire-prone shrublands in Patagonia. J. Veg. Sci. 26, 89-101

108. Blackhall, M. etal. (2017) Effects of biological legacies and herbivory on fuels and flammability traits: a long-term experimental study of alternativestablestates. J. Ecol. 105, 1309-1322

109. Nowacki, G.J . and Abrams, M.D. (2008) The demise of fireand "mesophication" of forests in the eastem United States. BioScience 58, 123-138

110. Noss, R.F. (2012) Forgotten Grasslands of the South: Natura History and Conservation, Island Press

111. Ludwig, D. et al. (1978) Qualitative analysis of insect outbreak systems: the spruce budworm and forest. J. Anim. Ecol. 47 , 315-332

112. Folke, C. etal. (2004) Regimeshifts, resilience, andbiodiversity in ecosystem management. Annu. Rev. Ecol. Evol. Syst. 35, 557-581

113. Chapin, F.S. et al. (2004) Global change and the boreal forest: thresholds, shifting states or gradual change? AMBIO 33 361-365

114. J ohnstone, J.F. etal. (2010) Fire, climatechange, and forestre silience in interior Alaska. Can. J. For. Res. 40, 1302-1312

115. Parr, C.L. et al. (2014) Tropical grassy biomes: misunderstood, neglected, and under threat. Trends Ecol. Evol. 29, 205-213

116. He, T. et al. (2019) Fire as a key driver of Earth's biodiversity. Biol. Rev. 94, 1983-2010

117. Stevens, N. et al. (2017) Savanna woody encroachment is widespread across three continents. Glob. Chang. Biol. 23 235-244

118. Bond, W.J. (2016) Ancient grasslands at risk. Science 351 120-122 
119. Bond, W.J . et al. (2019) The trouble with trees: afforestation plansfor Africa. Trends Ecol. Evol. 34, 963-965

120. Veldman, J.W. et al. (2019) On "The global tree restoration potential". Science 366, eaay7976

121. Baldocchi, D. and Penuelas, J. (2019) The physics and ecology of mining carbon dioxide from the atmosphere byecosystems. Glob. Chang. Biol. 25, 1191-1197

122. Bond, W.J . and Midgley, G.F. (2012) Carbon dioxide and the uneasy interactions of trees and savannah grasses. Philos. Trans. R. Soc. Lond. B Biol. Sci. 367, 601-612

123. Resco de Dios, V. (2016) When fire acts like an irrigation: compe tition release after burning enhances growth. Trees 30, 579-580

124. Pausas, J.G. and Keeley, J.E. (2019) Wildfires as an ecosystem service. Front. Ecol. Environ. 17, 289-295

125. van Mantgem, P.J. et al. (2016) Does prescribed fire promote resistance to drought in low elevation forests of the Sierra $\mathrm{Ne}$ vada, California, USA. Fire Ecol. 12, 13-25

126. Boisramé, G. etal. (2017) Managed wildfireeffectsonforestre silience and water in the Sierra Nevada. Ecosystems 20, 717-732

127. Svenning, J-C. et al. (2016) Sciencefor a wilderAnthropocene: synthesis and future directions for trophic rewilding research Proc. Natl. Acad. Sci. U. S. A. 113, 898-906
Suding, K.N. and Hobbs, R.J . (2009) Threshold models in restoration and conservation: a developing framework. Trends Ecol. Evol. 24, 271-279

129. Pausas, J.G. and Ribeiro, E. (2013) Theglobal fire-productivity relationship. Glob. Ecol. Biogeogr. 22, 728-736

130. Hoffmann, W.A. and Franco, A.C. (2003) Comparative growth analysis of tropical forest and savanna woody plants using phylogenetically independent contrasts. J. Ecol. 91 475-484

131. Charles-Dominique, T. et al. (2015) Functional differentiation of biomes in an African savanna/forestmosaic. S. Afr. J. Bot. 101 82-90

132. Koltz, A.M. et al. (2018) Global change and the importance of fire for the ecology and evolution of insects. Curr. Opin. Insect Sci. 29, 110-116

133. Archibald, S. et al. (2019) Aunified frameworkfor plantlifehistory strategies shaped by fire and herbivory. New Phytol. 224, 1490-1503

134. Pausas, J.G. et al. (2017) Flammability as an ecological and evolutionarydriver. J. Ecol. 105, 289-297

135. Ratajczak, Z et al. (2014) Abrupt transition of mesic grassland to shrubland: evidence for thresholds, alternative attractors, and regimeshifts. Ecology 95, 2633-2645 